\title{
Preparing effective experimental data for pharmaceutical patent applications from US and Japanese perspectives
}

"...it is important to consider the timing and types of data that should be included in a patent application and what considerations should be made with respect to filing a patent application during pharmaceutical R\&D."

\section{Background}

Scientific advances in the pharmaceutical technology area continue to further the state of the art and increase the level of understanding regarding how small-molecule drugs interact with the human body. Perhaps unexpectedly, these advances have made it more difficult to obtain patents for pharmaceutical inventions. As the level of technology considered to be 'known' to one of skill in the art increases, the bar to establishing non-obviousness of a discovery rises. Therefore, experimental evidence, such as pharmacological data, has become an indispensable tool in obtaining pharmaceutical patents. On the one hand, experimental data is required to show that the pharmaceutical inventions will work for their intended purpose. While on the other hand, experimental data is often also provided to show that a new technology has improved characteristics over previous technology and that such improvements would be unexpected and therefore non-obvious to one of skill in the art.

The standards and form of experimental data effective in obtaining patent protection are often quite different from those involved in gaining regulatory approval (e.g., at the US FDA or the Japanese Ministry of Health and Welfare) for the product covered by the patent. An invention covered by a patent does not necessarily represent the product itself, but rather the idea behind it and, therefore, experimental data included in a patent application or submitted during prosecution of the application is often necessary to support patentability of the technical idea behind the product.

The America Invents Act (AIA) has recently gone into effect in the USA [1]. This new law has generally converted the US from a first-to-invent system to a first-inventor-tofile system similar to most other countries. Accordingly, additional emphasis has been placed on the prompt filing of a patent application, even at an early stage of R\&D. An applicant can no longer rely on establishing a prior invention date if another inventor files a patent application to the same invention first. However, a hastily written application that does not contain experimental data may face very difficult prosecution and may have a decreased likelihood of issuing as patent.

Therefore, it is important to consider the timing and types of data that should be included in a patent application and what considerations should be made with respect to filing a patent application during pharmaceutical R\&D. This article provides guidance in developing a filing strategy for pharmaceutical patent applications from both US and Japanese perspectives. Also included are practical points to keep in mind regarding the timing and form experimental data should take in order to increase the likelihood of obtaining a patent covering a pharmaceutical product. In light of the global nature of both pharmaceutical R\&D and production, it has become increasingly important that a product receive robust international patent protection. As such, regardless of where a patent is originally drafted and filed, it must contain all required elements for satisfying the patent requirements of strategically relevant countries. This article will compare and contrast US patent practice to Japanese patent practice, focusing on case law and the rules and procedures of the patent office of each country.

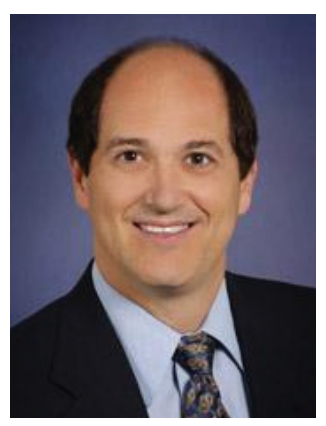

Daniel Altman

Author for correspondence: Knobbe Martens, 2040 Main Street, 14th Floor, Irvine, CA 92614, USA dan.altman@knobbe.com

\section{Christopher Sweeney}

Knobbe Martens, 925 Fourth Avenue, Suite 2500 Seattle, WA 98104, USA

Takuya Yasui Japan Patent Office, 3-4-3 Kasumigaseki, Chiyoda-ku TY0100-8915, Japan 


\section{Experimental data before filing a patent application}

Include all relevant data in an application, but avoid delays in filing

The experimental data included in a patent application as filed is often the most useful in the procurement of the patent. Additional data can be submitted at a later date, but it will not become part of the application. Some applicants make the mistake of leaving out data that may end up being vital years later when the patent application is under examination. For example, data regarding certain properties of a compound initially thought to be irrelevant may later help to distinguish it from prior art compounds. Timing of the filing of a patent application can be crucial to its successful prosecution, especially in crowded fields of technology. An application filed early without data may be insufficient to provide adequate written description and enablement and demonstrate non-obviousness of the technology [1,2]. However, an application containing extensive data may be rejected if it is filed even 1 day after a competitor's application. Applications can be filed in series as data become available to reduce the risks associated with the above situations.

In the USA, inclusion of large amounts of data in a patent application can lessen the risk of being seen as withholding relevant information from the patent office and can be useful during prosecution. However, submitting data after the filing date to support the claims of an application is generally accepted by the US Patent and Trademark Office (USPTO). Therefore, it is usually best to include all data available at the time of filing, but generally avoid delay in filing to generate additional data.

In Japan, the data included in the application as filed may be the only data that the applicant is able to reference to support the claims during prosecution. The applicant may later submit experimental data to support his argument. However, in certain circumstances, discussed in detail below, it is not possible to compensate for a deficiency of the application by merely submitting further data to the Japan Patent Office (JPO). It is important to include data sufficient to support the claims and show unexpected results over the prior art in the application as filed.

Delay all public disclosure of experimental data until after filing a patent application

While preparation of experimental data during $R \& D$ is important, it is also essential to keep it confidential prior to filing a patent application containing the data. In both the US and Japan, an invention is generally not entitled to a patent if the inventor has already disclosed the invention earlier than the applicable 'grace period'.
However, as discussed below, a grace period should only be utilized as a last resort. If the fundamental idea of an invention is shown in a public disclosure (including a clinical protocol for regulatory approval) prior to the applicable grace period, such disclosure can be cited by a patent office as anticipating or making obvious the claims of the application. Therefore, it is imperative to confirm with inventors that no public disclosures (even online disclosures) occur prior to the filing of a patent application.

\section{"If an applicant seeks a patent for an invention based on a new use of a known compound, the inclusion of experimental data to corroborate the effectiveness of the use is essential to patentability."}

In the USA, the best practice is to file a patent application before the public disclosure of any aspect of the invention. Although the USA has a 1-year grace period for disclosures by the applicant, such grace period is not applicable in all countries and publication prior to a filing date can severely limit international patent rights. Under the AIA, the 1-year grace period is far less robust than the grace period available under US patent law prior to the effective date of the AIA (16 March, 2013). For example, a third party disclosure based on an inventor's subject matter, but including variations or modifications may be considered prior art against the inventor's application if the application is filed after the third party disclosure.

In Japan, prior to the early 2000s when Japan proclaimed itself to be an 'IP-based nation', experimental data associated with an invention was often disclosed by inventors before the filing of a patent application, especially in university-related settings. Japan had a limited 6-month grace period to account for such disclosures and expanded the scope of applicable disclosure in 2011. However, the Japanese grace period has no bearing on a third party's disclosure of the invention before filing. Moreover, unless a formal request for applicability of the grace period is made at the time of filing, the grace period cannot be relied upon.

\section{Experimental data at the time of filing Composition of matter claims}

Pharmaceutical companies often develop strategies to obtain initial broad concept patents covering a new chemical compound and later seek to protect their R\&D by obtaining patents on selection inventions and applied inventions (e.g., new uses, formulations, combinations). While it is important to include data in the application sufficient to support enablement, written description and unexpected advantages of the 
technology, it is also important to avoid a delay in filing (while waiting for data results). As such, the decision regarding when to file a patent application should be approached carefully with an overall patent portfolio strategy in mind.

\section{Consider filing multiple patent applications} having different sets of experimental data Applicants often file a composition of matter application upon identification of the utility of a compound or racemate. Afterward, further research may scrutinize a specific structural aspect, isomer or salt of the compound to clarify the advantageous properties. At this stage, additional related or unrelated applications regarding such specific structures and utilities should be filed. However, experimental data provided in the first application may prevent additional applications from being patented. In some cases, an initial application includes a discussion of structures such as separated enantiomers to supplement the disclosure. However, as an exception to the practice of submitting all available data discussed above, if a second unrelated application to specific enantiomers or related structures is desired (e.g., when it is preferable to calculate patent term from the second filing date) the first application should not include extra experimental data that could anticipate or make obvious claims to those isolated compounds in later patent applications.

In the USA, under 35 U.S.C. \$101, no two patents may have identical claims, even if the inventors and assignee of both patents are the same. In addition, the judicially created doctrine of obviousness-type double patenting prevents the patenting of claims in one application or patent that are not 'patentably distinct' (or would be obvious over) claims of another application. The filing of a terminal disclaimer can obviate such a rejection, but requires that the second application disclaim any patent term beyond the term of the original application. Therefore, even if a prior filed application is not prior art under 35 U.S.C. $\$ 102$ (b) or 35 U.S.C. $\$ 103(\mathrm{a})$, it can still serve as the basis for a rejection under the judicially created doctrine of obviousnesstype double patenting. As such, when claiming related compounds in unrelated patent applications, it is important to carefully craft claim language to avoid such double patenting rejections.

In Japan, the Japan Patent Act has a statutory double patenting provision. Where two or more patent applications claiming identical inventions have been filed on different dates, only the applicant who filed the patent application on the earliest date shall be entitled to obtain a patent for the invention claimed [3]. A patent can also be rejected for being 'substantially the same' as another patent when there is only 'a minor difference in embodying the means for solving the problem' between them [4]. Determinations of whether inventions are the same or substantially the same are based only on the claimed invention, and therefore, experimental data provided in the first application is usually irrelevant to a double patenting rejection. Unlike the USA, the Japanese patent system does not have a terminal disclaimer practice.

\section{Do not include unnecessary disclosure that} reveals research \& development strategy

As there are many candidate compounds in the early stages of R\&D, inventors often file an application with claims to broad chemical structures covering a cluster of compounds that encompass prospective candidate compounds. However, it is important to keep in mind that the content of most patent applications will be published after a certain period of time [5]. Therefore, disclosure of every contemplated manufacturing example may reveal future R\&D strategy, which creates a risk that competitors become aware of the strategy, conduct similar research and file competing patent applications.

\section{Medical use or method of treatment claims Include pharmacological data specifically supportive of medical use or method of treatment claims}

For applications containing claims to medical uses or methods of treatment comprising a compound, pharmacological data is usually necessary to show the asserted utility of the compound. If an applicant seeks a patent for an invention based on a new use of known compound, the inclusion of experimental data to corroborate the effectiveness of the use is essential to patentability. Without such evidence, it is extremely difficult to establish whether the compound actually exhibits the new utility being claimed.

It is also vital to design experiments that directly compare the claimed subject matter to the known technology. For example, all conditions of a comparative assay should be identical except for the active compound. It is not enough to show improvement associated with the inventive data results; it must be clear that the improvement is directly caused by the claimed technology. This is an example of where the requirements for regulatory approval and the requirements for patentability diverge. Data showing the safety and efficacy of a claimed compound may be sufficient to obtain regulatory approval, but insufficient to prove patentability without data showing comparisons of that compound to known compounds.

In the USA, method of treatment claims often require more experimental data to establish written 
description and enablement than compound claims. The test for the written description requirement is whether the disclosure of the application reasonably conveys to those skilled in the art that the inventor had possession of the claimed subject matter as of the filing date. The test for enablement of a claimed invention is "whether one reasonably skilled in the art could make or use the invention from the disclosures in the patent coupled with information known in the art without undue experimentation" [6]. The enablement requirement does not preclude experimentation, just undue experimentation, and " $\mathrm{t}]$ he fact that experimentation must be complex does not necessarily make it undue, if the art typically engages in such experimentation" [7]. The enablement requirement is evaluated with reference to the knowledge and skill ordinarily possessed in the art. The USPTO bears the initial burden of establishing a lack of enablement by providing acceptable evidence or reasoning supporting a contention that the claimed invention is not enabled [8].

In Japan, the JPO does not allow 'method of treatment' claims, but regards the invention of medical compositions comprising certain compounds as a product invention characterized in its medical use. Since this use is interpreted as an element of the invention, experimental data is required in most cases to support that the composition can be effectively used as medicine [9]. The requirements for enablement for medical use invention are met if the following are sufficiently clear in the application: (i) which compounds are (ii) applied to what sort of pharmacological test system, (iii) what sort of result is obtained, and (iv) what sort of relationship the pharmacological test system has with the medicinal use of the claimed medicinal invention. Regarding (iv), in the case of a less well-established causal nexus to link experimental evidence (pharmacological data) with a claimed medical use, the evidence may not render the claimed use sufficiently supported.

\section{Claims to new dosages, formulations or combinations}

The primary hurdle in patenting claims to a new dosage, formulation or combination of compounds is showing that the claimed differences from the prior art are non-obvious. Changes in dosage or formulation of a compound or a combination of known compounds is generally considered obvious absent a showing that the claimed elements exhibit advantageous characteristics that would be unexpected to one of skill in the art at the time of filing. An application should include experimental data showing that the formulation or combination itself provides an unexpected advantageous result. A mere additive effect of each substance of a combination is generally not sufficient to constitute unexpected results over the prior art. Therefore, experimental data should be designed to show direct comparisons of the predicted additive effect of two compounds and the actual effect achieved when both compounds are administered together. Only when the combined administration provides a greater or different effect than what was expected is an argument of non-obviousness likely to be successful.

\section{Experimental data after filing the application}

At the time of filing, it can be difficult to predict every rejection that an application may encounter during examination. Very often, issues arise years after the filing of the application that were never contemplated by the inventors or their patent attorneys at the time of filing. In such cases, it is often necessary to submit experimental data during prosecution, well after filing, in order to overcome unforeseen rejections.

In the USA, any data generated after the filing of an application must be submitted through a declaration signed by an inventor or a person qualified in the technical field of the invention. Few restrictions are placed on the form the data may take and the USPTO will generally consider newly submitted data within certain time frames. If additional research is done, it is advisable to tailor the experiments to directly compare the process or product of a cited prior art reference with that according to the claims of the application. Data submitted to overcome an obviousness rejection must compare the invention to the most closely related prior art to establish unexpected advantageous results [10].

In Japan, it is possible to submit data during the prosecution of an application to establish an inventive step. However, if new effects of the claimed invention are purported in the new data, but not discussed in the application as filed, the JPO may consider such data as an improper introduction of new matter and maintain the rejection for lack of inventive step. In light of the principles of Japan's patent system, it is generally impossible to later make up for deficient enablement of the invention in the specification as of the filing. Hence, mere submission of experimental data to compensate for a deficiency would usually be regarded as inadmissible newly added content after the filing [11]. However, an applicant can point out the common general knowledge that may have been overlooked or not appreciated by the Examiner when making a rejection [12]. On that basis, an applicant may submit experimental data to support such an argument. 


\section{Conclusion}

Due to the increasingly global nature of pharmaceutical research and development, preparing a pharmaceutical patent application with an eye to the requirements of other countries is becoming even more important. Much of the considerations regarding experimental data apply to both US and Japanese practice. However, recognizing the differences in the two systems and adequately preparing for each can provide a strategic advantage in building a successful international patent portfolio.

\section{References}

135 USC $\$ 112(a)$.

2 Leahy-Smith America Invents Act.

3 Japan Patent Act Art. 39(1).

4 Examination Guidelines for Patent and Utility Model in Japan, Part II, Chapter 3, 2.4.

535 USC $\$ 122($ b); Japan Patent Act Art.64.

$6 \quad$ M.P.E.P. $\$ 2164.01$ quoting United States v. Telectronics, Inc., 857 F.2d 778, 785, 8 U.S.P.Q.2d 1217, 1223 (Fed. Cir. 1988).

\section{Financial \& competing interests disclosure}

The authors have no relevant affiliations or financial involvement with any organization or entity with a financial interest in or financial conflict with the subject matter or materials discussed in the manuscript. This includes employment, consultancies, honoraria, stock ownership or options, expert testimony, grants or patents received or pending, or royalties.

No writing assistance was utilized in the production of this manuscript.

$7 \quad$ M.P.E.P. $\$ 2164.01$.

8 M.P.E.P. $\$ 2164.04$.

9 Examination Guidelines for Patent and Utility Model in Japan, Part VII, Chapter 3, 1.1.2.

10 MPEP 716.02(e).

11 See, e.g., Intellectual Property High Court, Hei 17 (gyo-ke) 10042 (2007); Tokyo High Court, Hei 13 (gyo-ke) 354 (2001).

12 See, e.g., Examination Guidelines for Patent and Utility Model in Japan, Part I, Chapter 1, 2.2.1.5(1) and 3.2.4. 